\title{
SEISMIC ISOLATION AND ENERGY DISSIPATING SYSTEM FOR EARTHQUAKE RESISTANT DESIGN
}

\author{
Aayush Kumar \\ M.Tech, Department of Civil Engineering, \\ Madan Mohan Malaviya University of Technology, \\ Gorakhpur, Uttar Pradesh, India
}

\begin{abstract}
The concept of protecting a building from damaging effects of an earthquake by introducing seismic isolation and energy dissipating system. This concept was firstly emerged in the early 1970's. In China, the first energy dissipation structure was built at about same time. Over the past few decades, the ductility based conventional methods are being used for earthquake resistant design of structures. During a major earthquake, life safety can be achieved to the required level by these methods. In order to overcome this drawback in recent times, considerable attention has been given to the innovative, nonconventional method of earthquake resistant design \& this innovative method found more reliable and effective means of earthquake hazard mitigation. In this paper an attempt has been made to give the overview of this nonconventional system which includes the concepts of seismic base isolation and energy dissipation (Damper) and basic working principle of passive, active, hybrid and semiactive control system. Seismic isolation and energy dissipating system present an effective way to common seismic design for improving the seismic performance of structures. This technique reduces the seismic forces by changing stiffness and/or damping in the structures, whereas conventional seismic design is required for an additional strength and ductility to resist seismic forces. The research and development work of passive, active, hybrid devices are ongoing intensively. This technique is not yet very common, but a research activity is going on in order to investigate the behavior of the isolated building. Civil engineer, owner, contractors have great responsibility concerning application of these system.
\end{abstract}

Keywords - Seismic Isolation, conventional Method, Nonconventional Method, Damper, passive, active, hybrid, semi-hybrid control system.

\section{INTRODUCTION}

The vast devastation of engineered system and facilities during the past few earthquakes has exposed serious deficiencies in the prevalent design and construction practices.
The disaster has created a new awareness about the disaster preparedness and mitigation. The concept of protecting building from damaging effects to provide the structural safety and comfort by controlling the internal forces and displacement within the particular limits. The most wide method for protecting the structure against destructive effect of earthquake is to damp the seismic energy for limiting the seismic energy by the structural elements, it provides the resistance against earthquake in spite of using this method for certain level of protecting the structure could be damaged for real some times. One another methodology for protection of structures against earthquake is by isolating the building elements at the appropriate interval of differences in building and significant structural damage level could be minimized. The level of damage to the structural system depends upon the way in which structure dissipates the input seismic energy. In conventional method of earthquake resistant design the energy dissipation is achieved by material ductility. This method ensures the life safety but does not ensure the required damage control hence the functionality of structure after the earthquake becomes questionable. The required performance can be achieved by introducing non-conventional methods, of earthquake hazard mitigation techniques like base isolation, passive energy dissipation devices, and active, hybrid and semi hybrid control systems.

In seismic base isolation, the energy transferred to superstructure is considerably reduced by decoupling the superstructure and substructure. The entire superstructure acts as single unit and hence the storey drifts becomes negligible. The main objective of seismic isolation system is to decouple the building structure from damaging components of the earthquake input motion that is to prevent the superstructure of the building from absorbing the earthquake energy. The entire superstructure must be supported on discrete isolator whose dynamic characteristics are chosen to uncouple the ground motion. Displacement and yielding are concentrated at the level of isolation devices, and the superstructure behaves very much like rigid body. The main feature of the base isolation technology is that introduces flexibility in the structure. This help in further reducing the seismic response of building. 
In passive energy dissipation systems, a major portion of input energy is dissipated by mass of mechanical devices which may works on different principle like friction, shear deformations, metallic yielding, and fluid orificing etc. Thus the force introduced in the primary structure will be considerably reduced which consequently increases the ductility demand of the structure.

In active control systems, an algorithm based control unit along with actuators and sensors is used to reduce the response of the structure. In hybrid and semi active control system passive energy dissipation devices are embedded with active control systems to get desired structural control.

\section{SEISMiC BASE isolation.}

One of the most widely implemented and accepted seismic protection systems is base isolation. Seismic base isolation is a technique that mitigates the effects of earthquake by essentially isolating the structure and its components from potentially dangerous ground motion, their objective is to simultaneously reduce inter storey drifts and floor acceleration to limit or avoid damages, not only to the structure but also to its contents, in a cost effective manner.

Seismic base isolation is emerging as an alternative approach for earthquake protection of structures. The basic concepts to uncouple a structure from the ground by interposing a flexible element/bearing. Between the structure and foundation May buildings have been constructed on some type of rubber bearings, and such structure shown superior performance in earthquake.

The aim of base isolation is to minimize the energy that is transferred from ground motion to the structure by buffering it with a bearing layer at the foundation which has relative low stiffness. The bearing level has longer time period than the super structure, which reduces the force and displacement demands on the structure, allowing it to remain elastic and generally undamaged as a result of flexibilization; the natural time period of the past fixed base structures has a new natural period. The flexibility of the interposing layer between structure and its foundation lead to bigger fundamental period for structural assemble.

Base Isolation system consists of isolation unit with or without isolation component, where:

- Isolation unit are the basic elements of a base isolation system which are intended to provide the aforementioned decoupling effect to a building non building structure.

- Isolation components are the connection between isolation units and their parts having no decoupling effect of their own.

The fundamental principle behind the seismic base isolation is as follows:
- Decoupling the superstructure and substructure by means of elastic medium thus lengthening the fundamental natural periods of structure.

- Energy dissipaters or dampers in order to minimize the relative displacement of structure and its support.

- Providing enough rigidity in horizontal direction so that the structure acts like a fixed structure under minor earthquake and wind.

Schematic representation of conventional and isolated building under earthquake force as shown.

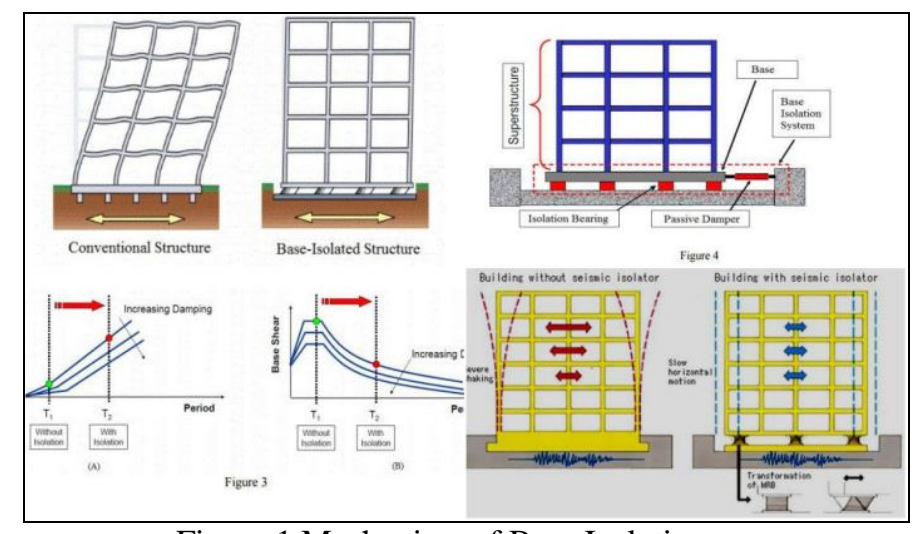

Figure 1 Mechanism of Base Isolation

A. Elements of Seismic Base Isolating System.

Seismic base isolator consists of energy dissipation care (lead plug), vulcanized rubber layers, steel reinforcing plates, bottom mounting plate and cover rubber. Energy dissipation care reduces earthquake. Forces and displacements by energy dissipation and also it provide wind resistance. Rubber layer provide lateral flexibility to system. Steel reinforcing plates provide vertical load capacity and also it confines lead core. Bottom mounted plate integrated with the isolators and it is used to connect the structure below and above isolator. Rubber is used to protect steel plate.

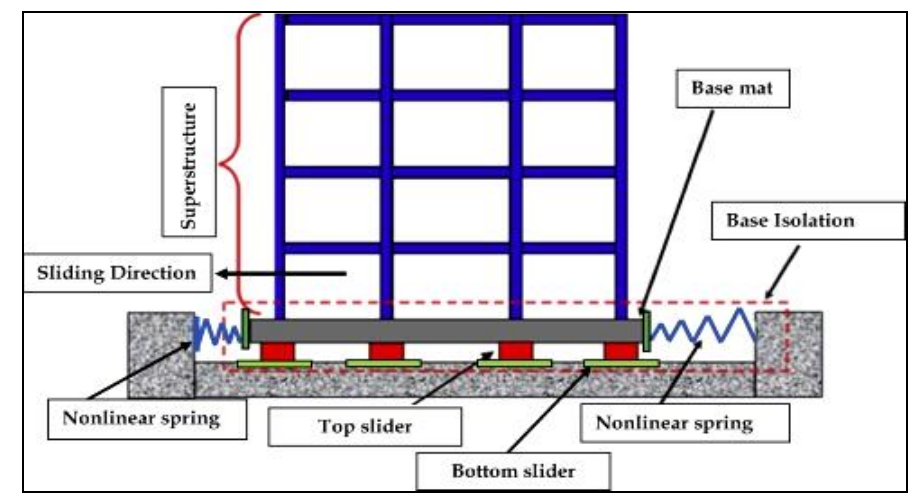

Figure 2 Elements of Base Isolation.

\section{B. Mechanism of base isolation-}

The isolation reduces the fundamental lateral frequency of the structure from its fixed base frequency (or increases the time 
period of the structure) and thus shifts the position of structure in the spectrum from the peak plateau region to the lower regions. Also it brings additional damping due to the increased damping introduced at the base level and thus further reduction in the spectral acceleration achieved.

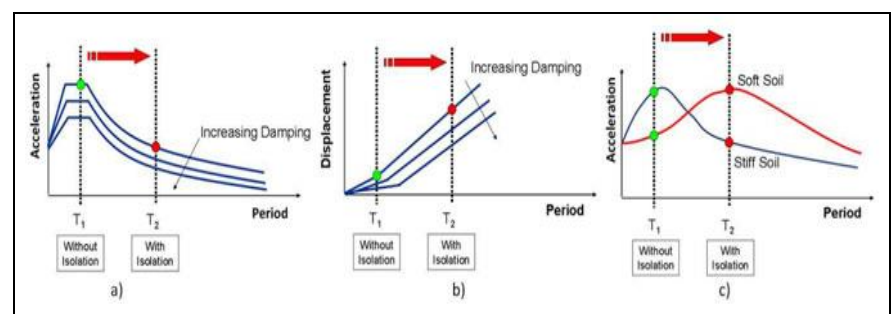

Fig. 3-Effects of base isolation: a) on spectral acceleration, b) on lateral displacement,

c) for different soil conditions

Figure 3 Mechanism of Base Isolation.

There is a base slab of mass Mb supported on bearing of lateral stiffness $\mathrm{Kb}$ and damping $\mathrm{Cb}$ in fig.

$$
\begin{gathered}
\mathrm{Tb}=2 \pi / \mathrm{wb} \\
\mathrm{Wb}=\mathrm{Kb} / \sqrt{ }(\mathrm{m}+\mathrm{mb}) \\
\eta \mathrm{b}=\mathrm{Cb} / 2(\mathrm{~m}+\mathrm{mb}) \mathrm{wb}
\end{gathered}
$$

$\mathrm{Tb}, \mathrm{Wb}$ and $\eta \mathrm{b}$ are those of isolated system for effective isolation, Tb should be as large as possible so that the force on the structure is small as seen by the response spectrum...

E.g. Loss Angels city hall, the world's tallest building to be retrofitted with base isolation.

\section{Principle of base isolation-}

The basic principle behind base isolation is that the response of the building modified such that the ground below is capable of moving without transmitting minimal or no motion to the structure above. A complete separation is possible only in an ideal system.

The relative displacement of ground and the structure is zero for a perfectly rigid, zero period structure, since the acceleration is induced in the structure, this relative displacement of the structure will be equal to the ground displacement. No structure is perfectly rigid or flexible, therefore the response of the structure will be between the two explained above maximum acceleration and displacement or function of earthquake for periods between zero to infinity during earthquake there will be range of periods at which acceleration in the building will be amplified beyond maximum ground acceleration, through relative displacements may not exceed peak ground displacement. Base isolation is the ideal method to cater this, by reducing the transfer of motion; the displacement of building is controlled. Displacement occurs at C.G of the structure for fixed base structures, which will be approximately two third heights for buildings and at isolation plane for base isolated structures with lesser displacement within the structure.

\section{TYPES OF SEISMIC BASE ISOLATORS.}

Many types of seismic isolators are being developed during the course of time. Following seismic base isolators are:

- Sliding system.

- Elastomeric bearing.

- Lead laminated rubber bearing.

- Friction pendulum bearing.

- Ball and socket bearing.

\section{i. Sliding System-}

These are simple in concept. It consists of a concave surface at bottom over which the superstructure id made to rest. Under the action of earthquake force, the superstructure undergoes displacement in the predefined constraints of sliding system. The original position of the structure is regained due to the restoring force produce because of concave bottom surface Fig; illustrates the sliding system.

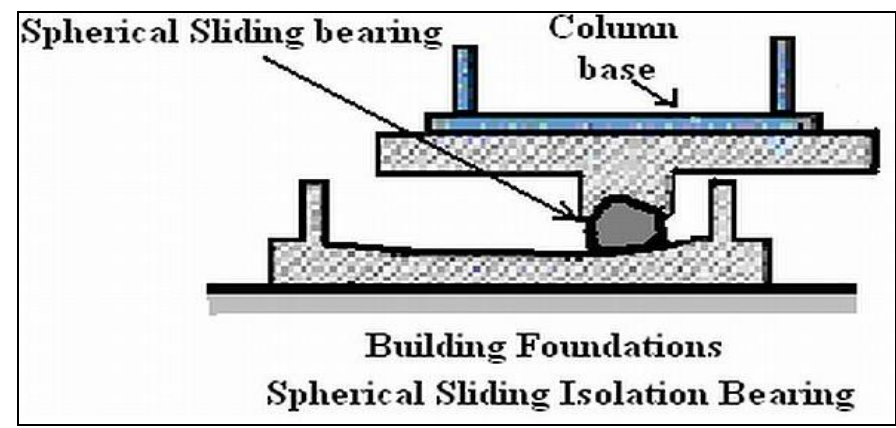

Figure 4 Spherical Sliding Isolation bearing system.

ii. Elastomeric(Rubber)Bearing-

These systems also have steel laminated rubber types and steel laminated rubber types with lead nucleus, along with the ones made of rubber and neoprene. The natural and artificial rubber bearings. These rubber bearings, which were used in bridge bearings have later been developed and have been named elastomeric bearings. These rubber bearings, which are widely used as seismic isolator. The rubber laminated isolators are formed through vulcanization of thin steel plates to rubber plates.

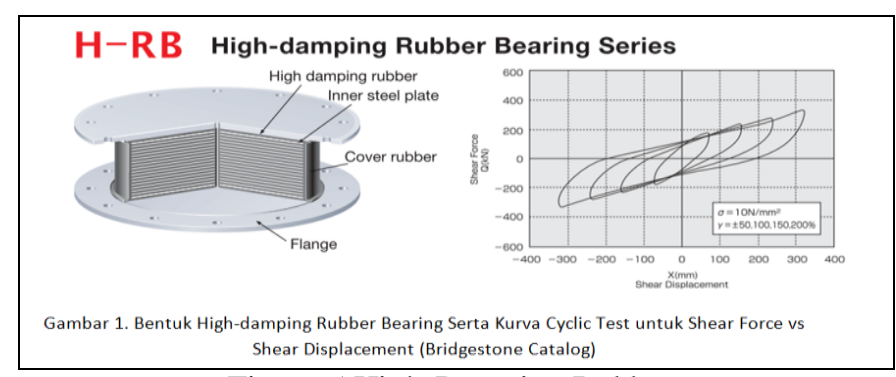

Figure 5 High-Damping Rubber.

\section{iii. Lead laminated Rubber Bearing-}

Lead laminated rubber bearing system is constituted by steel/rubber laminated layers with a lead nucleus embedded in 
the middle, and they are highly developed seismic isolators. Lead rubber bearing consists of thin horizontal layer of rubber which is bonded to steel plates to avoid excessive bulging under high vertical loads and a central lead core is introduced to have a damping effect in order to reduce the excessive displacement.

The William Clayton building in Wellington, New Zealand was the first building to be base isolated using lead rubber bearing in 1987.

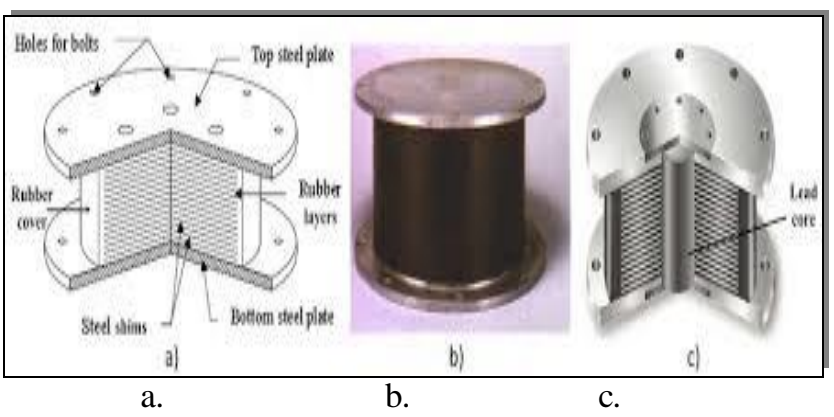

Figure 6 Elastomeric Bearing a. Natural Rubber Bearing b. Elastomeric Rubber Bearing c. Lead Rubber Bearing.

\section{iv. Friction Pendulum Bearing-}

Friction bearing system is the most extensively used kinematic system especially in base isolation. Pendulum system consists of a steel globe placed in two steel concave curved surfaces or a cylindrical member with global contact surfaces. In these parts special metals are used. The bearings, which have all the benefits of rubber bearings, through a bearing member which can slide on the global concave surface, it damps energy because it assumes position elevating the building during the lateral motion, and decrease the effect of earthquake a lot. These bearings can be used in spanning and in heavy roof systems, and also through mechanical properties of special metals in their structure; they can be successfully used in cold regions with danger of freezing.

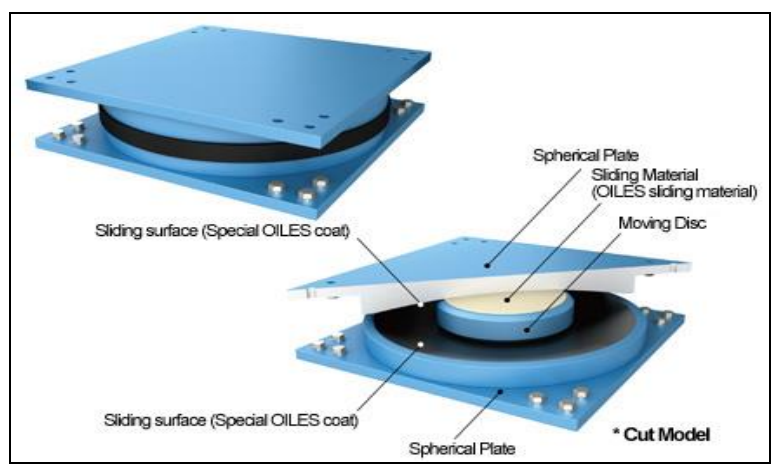

Figure 7 Friction Pendulum Device

\section{v. Spring-}

Steel spring is most likely used in mechanical application as in roller bearings. It is not adopted in structural application because it is flexible in both vertical and horizontal direction. This will increase service deflection.

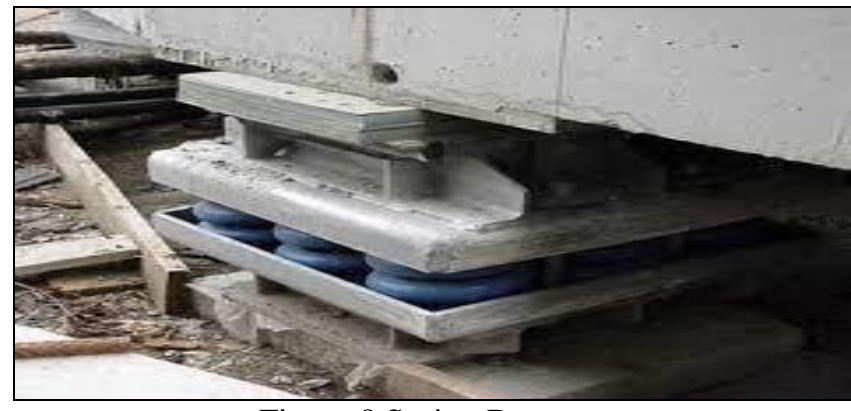

Figure 8 Spring Damper.

\section{Limitation of Base Isolation.}

- Initial cost of base isolated building comes out usually higher than conventional building due to additional cost of isolators and its installation.

- As the height of the building increases, the super structure cannot act as perfect rigid body and base isolation becomes ineffective. Therefore it applicable to limited height.

\section{ClasificAtion OF SEISMiC ISOLATED SYSTEM.}

Seismic isolation devices in the structures may be placed as in a way that the foundation of the structure is separated from its superstructure or specific sections of the building. Following classification was given below:

\section{A. Passive Energy Dissipating System.}

These systems compare of material and devices, which enhance damping, stiffness and strength, can be used for both rehabilitation of structures and new construction. These systems are characterized by their energy dissipating capacity in the structural systems in which they installed. These types of devices are always ready to perform to their capacity and their capacity does not depend on the excitation force. The different types of passive energy dissipating devices along with their working principle are described below:

\section{i. Viscoelastic Damper.}

Various types of energy dissipating devices utilizing copolymers to dissipate energy in shear deformation have been developed and tested by researchers. These devices significantly increase the capacity of the structure to dissipate the energy, but have little influence on the natural vibration periods; they are shortened by about 10 to $20 \%$. Viscouselastic damper consisting of layers of copolymer bounded with steel plates, the resulting almost hysteresis loop, and the 
damper installed in the diagonal bracing of a structure. Energy dissipated by relative motion between the outer steel flanges and the centre plate of the device.

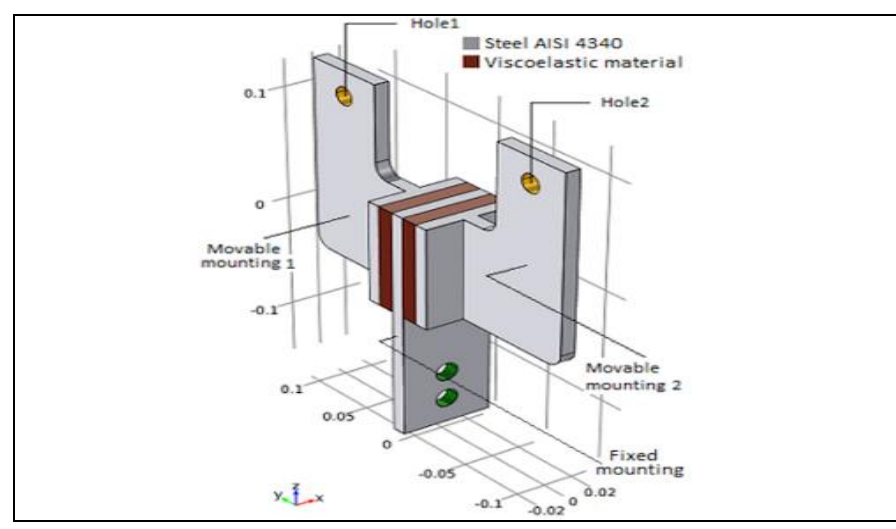

Figure 9 Viscoelastic Damper

\section{ii. Viscous fluid damper}

Viscous fluid damper are similar to shock absorber in a car. They consist of a closed cylinder contain viscous fluid like oil. A piston rod is connected to a piston head with small hole in it. The piston can move out of the cylinder. As it does this, the oil is forced to flow through holes in the piston head causing friction when the damper is installed in the building, the friction converts some of the earthquake energy going into the moving building into heat energy. The damper is usually installed as part of a building's bracing system using single diagonals. As the building sways to and fro, the piston is forced in and out of the cylinder.

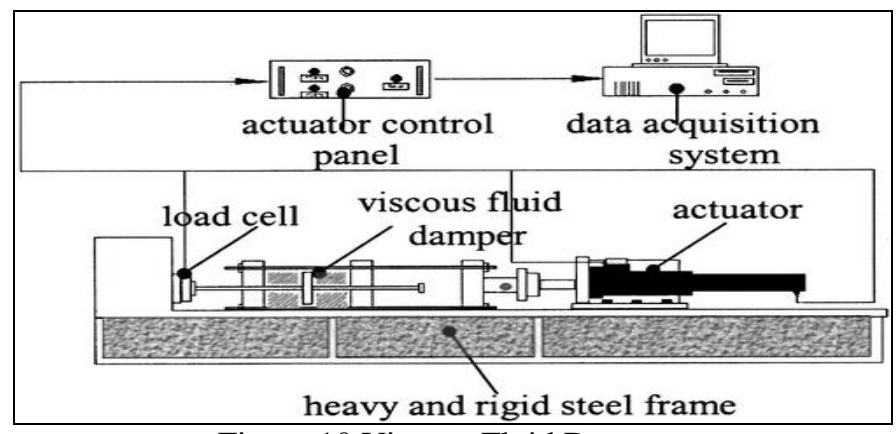

Figure 10 Viscous Fluid Damper.

\section{iii. Tuned Mass Damper.}

The tuned mass damper is a mechanical device used to decrease or eliminate unwanted vibration. The description tuned mass damper is often used in modern installation. It stabilizes against violent motion caused by simple harmonic vibration. A tuned damper reduces the vibration of a system comparatively light weight component so that the worst case vibration is less intense. Roughly speaking, practical systems are tuned to either move the main made away from troubling excitation frequency, or to add damping to a resonance that is difficult or expensive to damp directly.

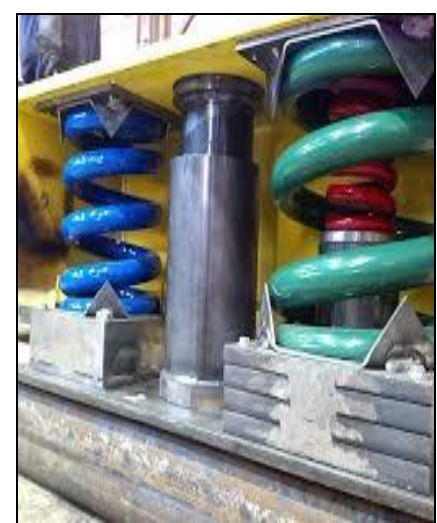

a.

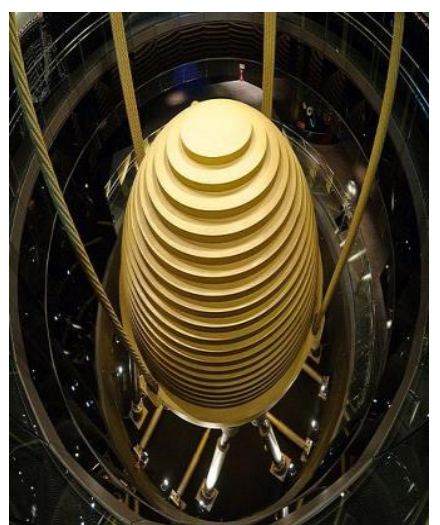

b.
Figure 11 a. Tuned Mass Damper-Thornton Tomasetti. b. Scheme Tuned Mass Damper.

\section{iv. Friction Damper.}

Various types of energy-dissipating devices, utilizing friction as means of energy dissipation, have been developed and tested by researchers. They increase the capacity of the structure to dissipate energy but do not change the natural vibration time periods significantly by about 10 to $20 \%$ one of these devices is the slotted bolted connection. (S.B.C).

This are designed to have moving parts that will slide over each other during a strong earthquake. When the parts slide over each other, they create friction, which uses some of the energy from the earthquake goes into the building.

The damper is made up from a set of steel plates, which have slotted holes in them, and they are bolted together. At high enough forces, the plate can slide over each other creating friction. The plate is specially treated to increase the friction between them. Figure shows typical friction damper.

\section{v. Metallic Damper.}

Metallic Damper is made up of steel. In this type, the energy is absorbed by metallic components that yield they are designed to deform so much when the building vibrates an earthquake, which they cannot return to their original position shape. This permanent deformation is called in elastic deformation. It uses some of the earthquake energy, which goes into building. There are different types of metallic dampers. X shaped damper are used where two braces meet. As the building vibrates, the braces stretch and compress, pulling and pushing the damper sideway and making it deform.

\section{vi. Tuned Liquid Damper.}

This works on the similar principle of tuned mass damper (TMD). In effect, a secondary mass in the form of a body of liquid is introduced into the structural system and turned to act as a dynamic vibration absorber. They have their primary applications in controlling wind induced vibrations. When compare to TMDs tuned liquid damper (TLD) include low initial cost, ease of frequency tuning and virtually free of maintenance. 


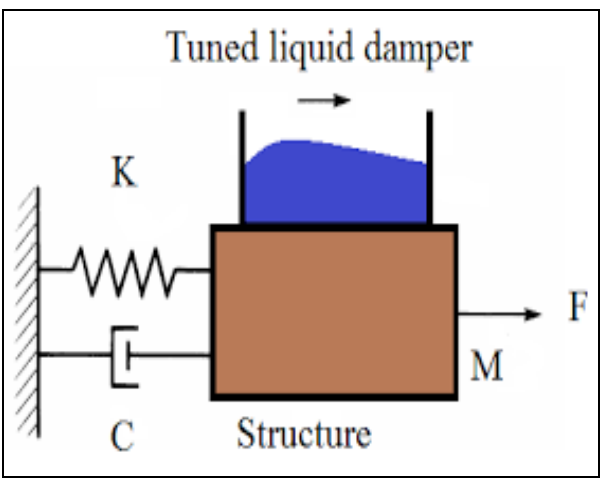

Figure 12 Tuned Liquid Damper

B. Active control Systems.

In active control system the resistant forces are not fixed and are dependent on the external exicitation. This system is a combination of computes science data processing sensing technology. Structural dynamics and wind and earthquake engineering.

The operation mechanism of active control system is based on providing a continous energy from outside. That is why the cost of setting up these system is high. The system can control the acceleration, displacemet or the velocity of the structure. The design of active control system is independent from the ground motion in the following way. The system is changes its rigidity or the quantity of motion. Therefore the such factors such as the uncertainity or unpredictable of the future ground motion are not importatnt in the design that makes use of active control sysytems. There are main application forms of active control system.

\section{i. Active Mass Damper.}

In the system, by forming actulator control force, the acceleration, displacement and velocity of the structure affected by lateral forces are controlled by computer system.

\section{ii. Active Variable Stiffness.}

In this system, there is no need for forming of actuator control force. However, Elemination the resonance that results from conciding of fundamental period of the system and making the corresponding design. They are developed for utilization in case of strong ground motion.

iii. Active Passive Composite Tuned Mass Damper.

The hybrid structural, control system, which were developed in the recent years, are based on joint utilization of both active and passive system.

\section{Hybrid Control System.}

It is a combination of active control and passive dissipation systems. The power required to operate this system is comparatively much lesss than that of an active control system. In this type of system a portion of energy is dessipated by passive energy dessipation devices and hence load on the active control system is reduced and consequently required power is also less. A side benefit of hybrid system is that, in case of power failure, the passive components of the control still offer same degree of protection, unlike fully active control system. The schematic representation of hybrid control system is shown.

\section{Semi Active Control System.}

This type of system is similar to the hybrid control system the difference between two system is semi active control system controls actulstors do not add mrchanical energy directly into structure. Hence they are also often called as controllable passive devices. Due to the presence of PEDs this system also has a benefit of partial protection even in the case of a power failure, similar to the hybrid control system.the sistamtic representation of semi control system is shown in fig.

\section{SOME OF THE TYPICAL CIVIL ENGINEERING STRUCTURE IN WHICH BASE ISOLATION TECHNIQUE IS EMPLOYED.}

\section{a)New Zealand Parliament House.}

New Zealand Parliament House and Library, both are historical Buildingd constructed in 1899 and 1922 respectively the lateral load resisting systems seismically vulnerable unreinforced masonary. Seismic isolation chosen over conventional strengthining techniques to maintain the historic fabric of the building the isolation system comprises 145 lead rubber bearings, 230 high-damping rubber bearing and 42 sliders. Installtion of the isolators required strengthing of basement walls and columns, and provision of floor diaphrams. The retrofit involves re-piling the building with lead rubber bearings and rubber bearing in the supports, as well as cutting a seismic gap in the $500 \mathrm{~mm}$ thick concerete wall.

Expected performance- The effect of the isolation is calculated as increasing the fundamental period from a value of 0.45 to 2.5 seconds. During an earthquake the building will be able to move in any direction on a horizontal plane up to the distance of $300 \mathrm{~mm}$. the total cost for the restoration and seismic retrofit of these two buildings was approximatly US $\$ 90$ millions.

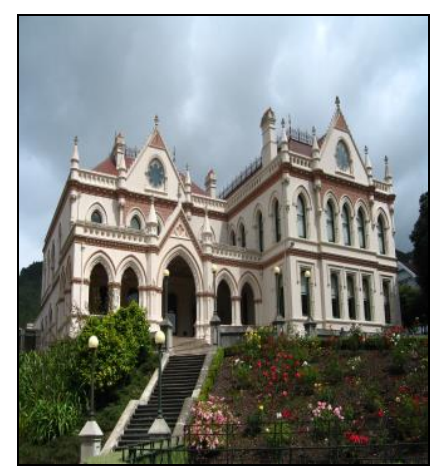

a.

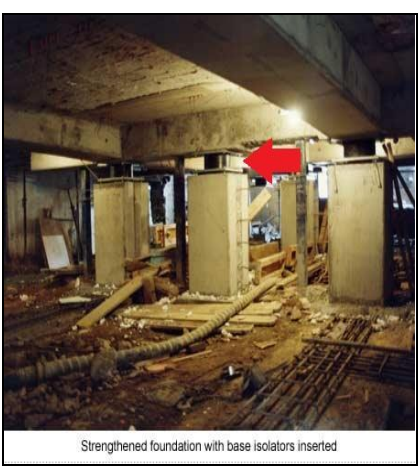

b.
Figure 13 a. New Zealand Parliamentary Library gobeirne b. Strengthened Foundation with Base Isolators.

b)San Fancisco City Hall 
San Francisco City Hall in san Francisco, california. Is a example of retrofit application of laminated -rubber-bearingsystem in isolated-system. Constructed in 1915 to replace the previous structure that was destroyed in the 1906 san Francisco earthquake, this building is an outstanding example of classical architecture and is listed in the national Register of Historic places. The five storey building with its dome rising $300 \mathrm{ft}$ above the ground floor is $309 \mathrm{ft}$ by $408 \mathrm{ft}$ in plan,occupying two city blocks. Subtailtial damage sustained from the 1989 Loma Prieta Earthquake, centered about 60 miles away,necessitated repairs and strengthening. The fixedbase fundamental period of vibration of the building is approximately 0.9 secs, implying ductility demands can be imposed on the structure by strong shaking expected at the building site from an earthquake centred on a nearby segment of the San Andreas fault. To improve the earthquake resistance of this structure, base isolation was adopted especially because it preserved the historic fabric of building this retrofit project was completed in 1988.

The isolation system consisted of 530 isolators, each a laminated rubber bearing with lead plugs, located at the base of each column and at the base of the shear walls.the 21-inhigh bearing varried from 31 to 36 in diameter. The columns are supported on one or more isolators under s cruciformshaped steel structure; multiple isolators were provided for the heavily loaded columns. Installation of isolators proved to be very complicated and required shoring up the columns, cutting the columns, and tranferring the column loads to temporary supports. The isolated building is estimated to move 18 to 26 in. at an isolation period of $2.5 \mathrm{sec}$ for a design earthquake with peak ground accelration of $0.4 \mathrm{~g}$. to permit this motion, a moat was constructed around the building to provide a minimum seismic gap of 28 in.flexible joint were provided for utilites-plumbing,electrical, and telephone lines-crosing this moat space to accommodate movement across the isolation system.

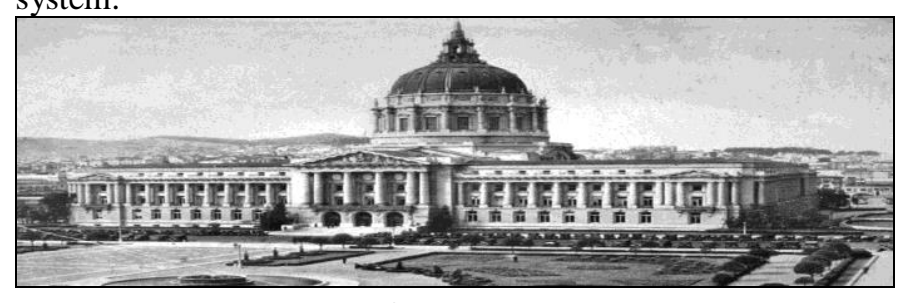

a.

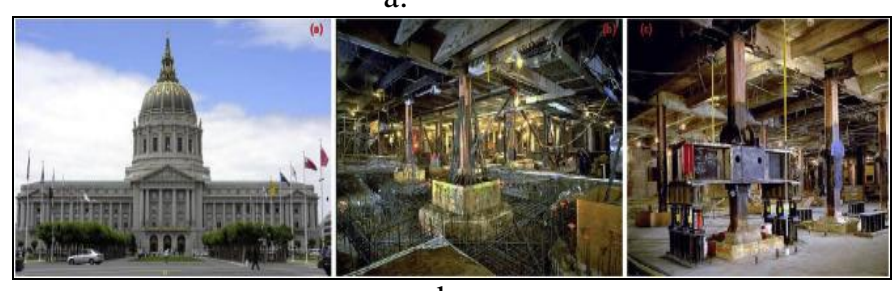

b.

Figure 14 a. San Francesco's City Hall. b. laminated Rubber System.

c)International Terminal San Francisco Airport
New construction using base isolation is the new (completed in were designed to remains operational after 8 magnitude earthquake on the San Andreas Fault approximately 3 miles away. To achive this performance goal it was decided to isolate the superstructure, which consists of steel concentric and ecentric braced frames with fulley welded moment connections. The isolated system consists of 267 isolators, one at the base of each column. Each isolator is a friction pendulum sliding bearing. The cast steel bearing consist of a stainless steel spherical surface and articulated slider, which allows a lateral displacement up to $20 \mathrm{in}$. and provides an isolation period of $3 \mathrm{sec}$.

Base isolation had the effect of reducing the earthquake force demands on the super structure to $30 \%$ of the demands for a fixed-base structure. With this force reduction it was feasible to design the superstructureb to remain essentially elastic and hence undamaged under the selected design earthquake with peak ground acceleration of $0.6 \mathrm{~g}$.

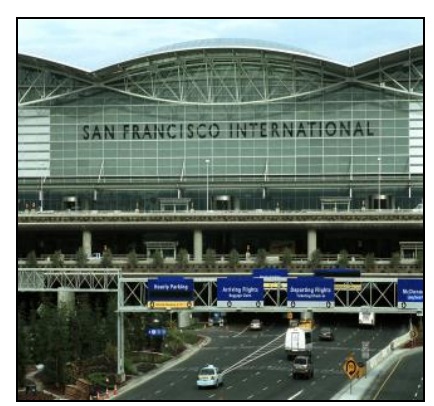

a.

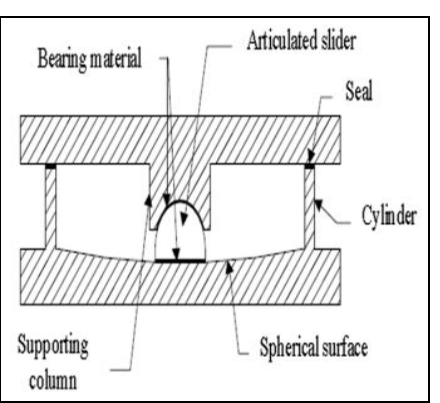

b.
Figure 15 a. San-Francisco-International-Airport b. Friction Pendulum Damper.

\section{d) Los Angeles City Hall, California (retrofit)}

It is the world largest Retrofited building. The total floor area close to $83,000 \mathrm{~m} 2$. City Hall (Fig. 14) has been placed on top of a mechanical system of 475 high damping rubber isolators, 60 sliders, and 52 mechanical viscous dampers employing base isolation technology that will dampen the violent movements of the earth during a seismic event. Also, 12 viscous dampers are installed between the twentyfourth and twenty-sixth floors to control interstory drifts at these softstorey levels.

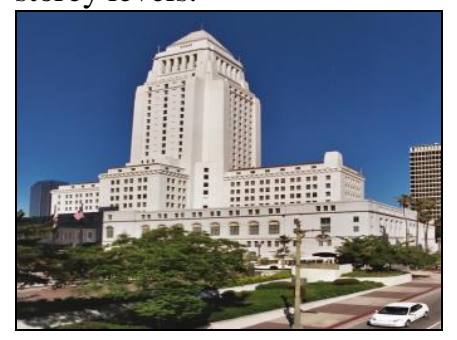

a.

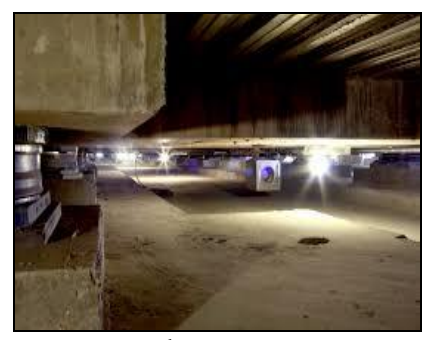

b.
Figure 16 a. Los Angeles City Hall Renovation. b. High damping Rubber Isolators. 


\section{e) Bhuj Hospital Gujrat, India}

The first isolated structure is the new $30,000 \mathrm{sq} \mathrm{m}$. with 300 beds, Bhuj Hospital, Gujrat reconstructed after the devascating earthqukae of 26 Jan 2001. It is reputed to be able to stand a force tremor on the richter scale 10. It is being founded on ROBISON seismic lead rubber bearings which give it the highest possible earthquake protection. This will protect the pateints and ensure that the hospital will remain operational following futre seismic attacks.

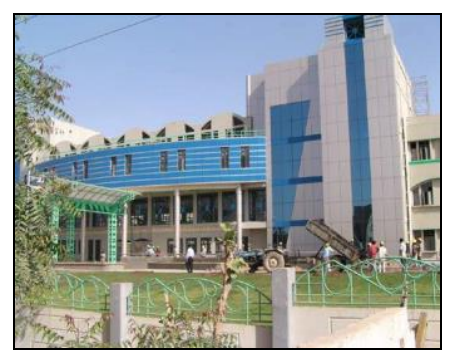

a.

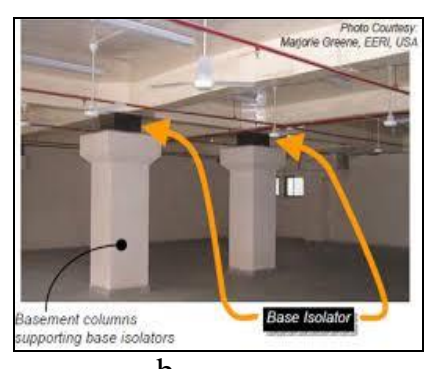

b.
Figure 17 a. Bhuj Hospital Gujarat, India.

b. Seismic Rubber Bearing.

\section{CONCLUSION}

- The following conclusion was considered by drawing various non-conventional methods of earthquake resistant design.

- The non-conventional method found to be more reliable and effective earthquake resistant design techniques, with a good reduction in response of the structures when compared to conventional method.

- This technology prevents the collapsing of buildings during earthquake, but today, the design that aim to maintain comfort in addition to earthquake security on the foreground.

- It is seen from the past experiences that seismic isolation provides a considerable decrease in acceleration and shear forces that effect the building; prevents the excess load on the existing superstructure and foundation system by decreasing the effect of lateral force during an earthquake; improves the behaviors of both horizontally and vertically irregular structures by the architectural consideration; prevents, at large scale, structural and non structural damages; prevent the sliding and turning over of either furniture and equipment or prevent the people from getting injured from this events; the most importantly, provides life security.

- Based on hysteric curve, structure with high damping rubber bearing and base isolation system can absorb the earthquake energy most efficiently.

\section{ACKNOWLEDGEMENT}

This research was partially supported by Madan Mohan Malaviya University of Technology. I thank to my colleagues Hari Madhav Singh, Shubhendra Mall, Annu Dubey from Madan Mohan Malaviya University of Technology. who provided insight and expertise that greatly assisted the research, although they may not agree with all of the interpretations of this paper. I would also like to show my gratitude and thankful to Asst. Prof. Mr. Madan Chandra Maurya, Madan Mohan Malaviya University of Technology. For assistance with Seismic Isolation \& Passive Energy Dissipating System with their Applications. for comments that greatly improved the manuscript.

\section{REFERENCES}

[1] PaN Peng, Ye Lieping, Shi Wei \& Cao Haiyun, (2012) "Engineering Practise Of Seismic Isolation And Energy Dissipation structure in china” vol. 55, Pg. 3036-3046.

[2] Torunbalci Necdet, (2004) "seismic isolation and energy dissipating systems in earthquake resistant design" 13th World Conference on Earthquake Engineering Vancouver, B.C., Canada Paper No. 3273 August, 2004.

[3] Petrina Bogdan, Pasca Stefania and Mureşan Ioana, (2011) "Seismic isolating systems classification, properties and utilization." Buletinul institutului politehnic din iaşi publicat de universitatea tehnică „gheorghe asachi” din iaşi tomul liv (lviii), fasc. 3, 2011.

[4] Adithya G. S., Shankarling Mandewali S., Dr. Narendra H., (2016) "Seismic Energy Dissipation: Art of the Scenario”. International Research Journal of Engineering and Technology (IRJET) e-ISSN: 2395 -0056, p-ISSN: 2395-0072 Vol.03-2016.

[5] Farissi Armroyini,(2009) "Design and Analysis of base isolated structures", International conference on earthquake Resistantance engineering structures, At Coruna, Spain Vol.9, 2009.

[6] Chopra Anil K.,(2007) "Dynamics of structuresEarthquke response of inelastic systems. Pg. 293 - 340.

[7] Chopra Anil K.,(2007)"Dynamic of structures" Earthquake Dynamic of Base - Isolated Building Pg. 777796.

[8] Damodardarasamy S.R. \& Kavitha S.,(2013) Basics of structural Dynamics and Aseismic Design, "New Techniques in Aseismic Design. ” Pg. 303-313.

[9] Agarwal Pankaj \& Shrikhande Manish,(2013) Case Study Seismic Retrofitting of RC Building By Seismic Base Isolation Pg. 571-573.

[10] Gupta Nikita, Sharma Dipali ,Poonam,(2014) State Of Art Review-Base Isolation for Structures International Journal of Scientific \& Engineering Research, Volume 5, Issue 5, ISSN 2229-5518, 2014.

[11] “Seismic Base Isolation”,(2020) Wikipedia, 2020. 
[12] Torunbalci N.,(2003) "Earthquake protective systems in civil engineering structures - evolution and application." Latini G, Brebbia C.A, Editors. Earthquake Resistant Engineering Structures IV, Southampton, Boston: WIT Press, 2003:359-368.

[13] Olariu I,(1995) "Passive control and base isolation". Proceedings of the 10th European Conference on Earthquake Engineering. Vienna, Austria, Rotterdam:AA Balkema, 1995.

[14] "FEMA, (1997a), NEHRP guidelines for the "seismic rehabilitation of buildings", Federal Emergency Management Agency, Report FEMA-273, Washington DC, 1997. 